\title{
A case of cardiac arrest following Brugada syndrome as a rare disorder
}

\author{
Seyed Reza Habibzadeh1, Samaneh Abiri², Saeed Barazandehpour ${ }^{3}$, Mohammad Javad Zarei ${ }^{4}$, Mahdi \\ Foroughian', Hamideh Akbari ${ }^{5}$, Navid Kalani ${ }^{6,7}$, Esmaeil Rayat Dost ${ }^{2 *}$, Seyed Hamed Hojati ${ }^{8}$
}

'Department of Emergency Medicine, Faculty of Medicine, Mashhad University of Medical Sciences, Mashhad, Iran 2Department of Emergency Medicine, Jahrom University of Medical Sciences, Jahrom, Iran ${ }^{3}$ Department of Emergency Medicine, Kerman University of Medical Sciences, Kerman, Iran ${ }^{4}$ Department of Emergency Medicine, Shiraz University of Medical Sciences, Shiraz, Iran ${ }^{5}$ Department of Emergency Medicine, Tehran University of Medical Sciences, Tehran, Iran ${ }^{6}$ Critical Care and Pain Management Research Center, Jahrom University of Medical Sciences, Jahrom, Iran ${ }^{7}$ Research Center for Social Determinants of Health, Jahrom University of Medical Sciences, Jahrom, Iran ${ }^{8}$ Student Research Committee, Jahrom University of Medical Sciences, Jahrom, Iran

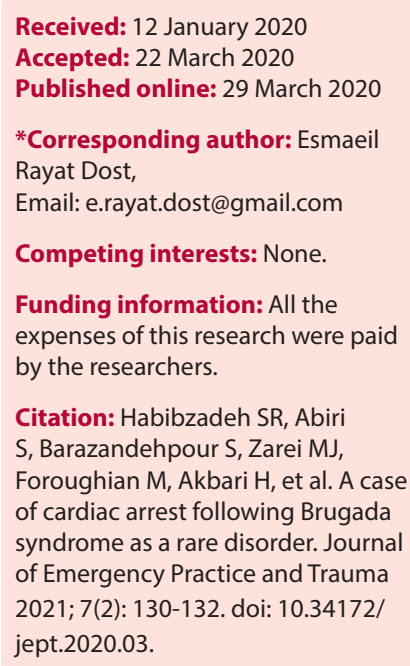

\begin{abstract}
Objective: Brugada syndrome (BrS) is a disorder in which the electrical activity in the heart is abnormal and affects individuals with cardiac dysrhythmia. In the present study, we introduce a case diagnosed with $\mathrm{BrS}$, admitted to intensive care unit (ICU) and received treatments following sudden cardiac arrest.

Case Report: The patient was a male 25-year-old medical student enrolled in the sixth academic year who suffered from loss of consciousness due to sudden cardiac arrest. The patient immediately received cardiopulmonary resuscitation (CPR) measures, was visited by a cardiologist and a neurologist, and was consequently treated with medications. After an 8-day stay in the coronary care unit (CCU), the patient regained his level of consciousness and he was transferred to the ICU of Faghihi hospital in the city of Shiraz, Iran. Being diagnosed with $\mathrm{BrS}$ and following pulmonary aspiration treatments, he finally implanted with an implantable cardioverter defibrillator (ICD).

Conclusion: Fortunately, necessary measures had been taken on time for the introduced patient and he was discharged with full recovery after 6 days.

Keywords: Brugada syndrome (BrS), Cardiac arrest, Implantable cardioverter defibrillator (ICD).
\end{abstract}

\section{Introduction}

Brugada syndrome $(\mathrm{BrS})$ is known as a primary electrical problem with the heart affecting individuals with cardiac dysrhythmia overnight (1). In this disease, an inherited genetic defect happens in association with an autosomal dominant sequence. Mutation in sodium voltage-gated channel alpha subunit 5 gene, which is responsible for encoding of the sodium channels in the heart, can lead to BrS. It should be noted that a genetic mutation can result in an imbalance between the movement of the ions inside and outside of myocytes and leads to sensitivity to dangerous ventricular arrhythmias (2). Electrocardiogram (ECG) manifestations of this syndrome also include the ST segment elevation in a down-sloping form in the right chest leads, similar design to the right bundle branch blocks especially in the lateral leads, as well as an increase in the J point (1). The prevalence rate of this disease has been estimated by 5 cases per 1000 individuals and it was identified as the second leading cause of death in men aged under 40, following traffic accidents, especially in countries where the disorder is thought to be endemic (3). This study is a case report of a patient diagnosed with $\mathrm{BrS}$, admitted to the intensive care unit (ICU) and received treatments following sudden cardiac arrest.

\section{Case Presentation}

The patient was a male 25-year-old medical student enrolled in the sixth academic year whose level of consciousness suddenly fell at 12:50 PM due to sudden cardiac arrest, with no family history of heart disease, after a heavy meal at the self-service restaurant of Peymanieh hospital in the city of Jahrom, Iran. He immediately 
received cardiopulmonary resuscitation (CPR) according to the American Heart Association (AHA) guideline. The medications used during the CPR were epinephrine (1 $\mathrm{mg}$ every 5 minutes for 5 times), amiodarone $(150 \mathrm{mg})$, magnesium sulfate $(2 \mathrm{~g})$, and lidocaine (1 ampoule with intravenous infusion).

Together with intubation, the initial cardiac rhythm was reported polymorphic ventricular tachycardia (VT). After receiving double 200-J biphasic electrical shocks and closed-chest cardiac massage for 10 minutes, the patient's cardiac rhythm became of sinus type and he was transferred to the coronary care unit (CCU) and received mechanical ventilation. The patient was also examined by a cardiologist and a neurologist and received medications including Inderal, lidocaine, piracetam, Depakin, and Levebel. Due to aspiration of food, infectious disease consultation was requested and broad-spectrum antibiotics (i.e. vancomycin and meropenem) began for him. Based on the measures taken, the CT scan of the patient's brain was reported normal and no hypoxicischemic symptoms were observed. Laboratory tests, especially those for cardiac enzymes were also at a normal level. Moreover, the electrocardiogram (ECG) results were reported to be normal. Furthermore, the ECG results of the patient showed an elevation in ST segment in the V1 lead ECG (Figure 1). After an 8-day stay and receiving care services in the $\mathrm{CCU}$, the patient regained his level of consciousness and was transferred to the ICU of Faghihi hospital in the city of Shiraz. Being diagnosed with BrS and following pulmonary aspiration treatment, the patient was implanted with an implantable cardioverter defibrillator (ICD).

\section{Discussion}

$\mathrm{BrS}$ is member of a group of disorders classified as primary arrhythmia syndromes. This syndrome has different asymmetric conditions with diverse etiologies, but common genetic bases and lack of cardiac structural abnormalities are recorded in BrS cases. Interestingly, some of these syndromes have been recently reported, but their pathophysiology has not been still fully understood and their definitions are also evolving (4). The present study reported a case diagnosed with BrS, admitted to the ICU and underwent treatments due to sudden cardiac arrest. It should be noted that BrS diagnosis is based on a special ECG pattern. In fact, there are three different ECG patterns in patients affected with BrS. At different times, three patterns may be also observed in a patient. However, one of these patterns can be considered as BrS diagnosis. Type-1 ECG pattern is manifested by elevation in ST segment of coved type, which is greater than $2 \mathrm{~mm}$ on most right chest leads (V1-V3) followed by the emergence of invert $\mathrm{T}$ waves (2). In this study, examining the patient's ECG showed elevating ST segment in the V1 lead. In the study by Moradi Moghadam, a case was reported with immediate CPR due to cardiopulmonary arrest

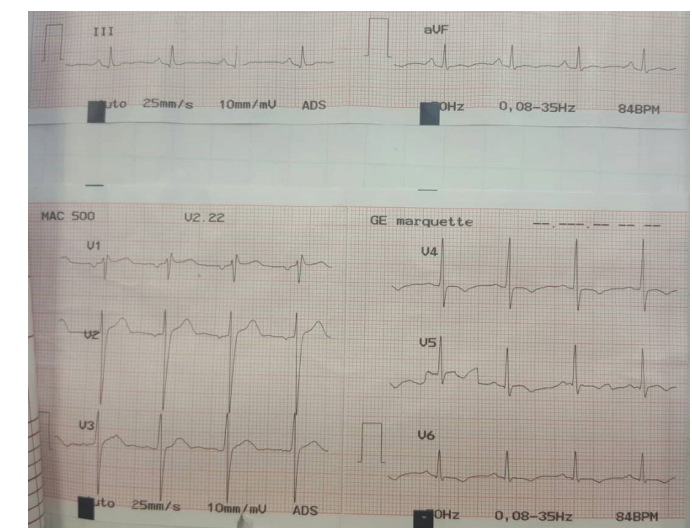

Figure 1. ECG of patient.

with ventricular fibrillation (VF) rhythm and received mechanical ventilation after CPR and was diagnosed with ischemic-hypoxic encephalopathy. According to the ECG results, the ST segment was observed in V1-V3 and lateral leads. Based on the given ECG, mild mitral insufficiency was reported (5). But, in the present study, the ECG and the CT scan results of the patient's brain were reported normal and no ischemic-hypoxic symptoms were observed. In a similar line, Eftekhari reported a case of $\mathrm{BrS}$ treated with acute myocardial infarction. According to the patients' ECG, elevation in ST segment was reported; but coronary angiogram did not show any signs of coronary artery disorders or myocardial infarction. Finally, BrS was reported in this patient following further examinations (6). This finding is consistent with the results of our investigation. In a study on 300 patients with no BrS symptoms, it was also noted that the occurrence of this syndrome in multivariate models was linked only to VT or VF (7). In addition, in a study of 21 patients suffering from BrS; 14 cases were reported with VT or VF, polymorphic VT was also recorded for 19 out of 21 cases, while VF was observed in 4 cases and 2 of them were following polymorphic VT (8). In the present study, the patient's cardiac rhythm was reported as polymorphic VT after a preliminary examination of his ECG results. Providing a comprehensive review, Morita et al (9) also reported that psychological stress (10) of the medications and increased activity of the vagus nerve (11-13) could increase the ST segment elevation. Whereas no clear scientific relationships have been observed between acute disorder of ST segment and ventricular arrhythmias, several reports have highlighted such an association (1417). But the point to note in this case report is that the patient suffered a loss of consciousness immediately after a long shift work and subsequent heavy meal in the selfservice restaurant of Peymanieh Hospital; so it seems that increased activity of the vagus nerve could have a crucial role in the sudden cardiac arrest.

\section{Conclusion}

Although BrShas a verylow prevalence rate, the occurrence 
of irreparable damage to patients can be prevented if it is diagnosed and patients are transferred to medical centers as soon as possible. Therefore, ECG patterns in BrS need to become clear for medical teams. Fortunately, necessary measures had been taken on time for the given patient in this report and he escaped certain death.

\section{Authors' Contributions}

All authors contributed equally to study design, drafting article, reading critically and accepted finally proof.

\section{Ethical Issues}

Informed consent form was obtained from the patient for the publication of this report.

\section{Acknowledgements}

We would like to thank the Clinical Research Development Unit of Peymanieh Educational and Research and Therapeutic Center of Jahrom University of Medical Sciences for providing facilities to this work.

\section{References}

1. Antzelevitch C, Brugada P, Borggrefe M, Brugada J, Brugada R, Corrado D, et al. Brugada syndrome: report of the second consensus conference: endorsed by the Heart Rhythm Society and the European Heart Rhythm Association. Circulation 2005; 111(5): 659-70. doi: 10.1161/01.cir.0000152479.54298.51.

2. Benito B, Brugada J, Brugada R, Brugada P. Brugada Syndrome. Rev Esp Cardiol (Engl Ed) 2009; 62(11): 1297 315. doi: 10.1016/S1885-5857(09)73357-2.

3. Khatami M, Ghanei Yakhdan Z. Novel nucleotide changes in mitochondrial COXII, cytochrome B and tRNAGlu genes in patients with Brugada syndrome. Journal of Shahid Sadoughi University of Medical Sciences 2014; 22(1): 9818. [In Persian].

4. Antzelevitch C, Yan GX, Ackerman MJ, Borggrefe M, Corrado D, Guo J, et al. J-Wave syndromes expert consensus conference report: Emerging concepts and gaps in knowledge. Europace 2017; 19(4): 665-94. doi: 10.1093/ europace/euw235.

5. Moradimoghadam O, Sedaghat A, Niakan M, Hajiesmaeili MR, Seifi S, Soleimanirad R. Sudden cardiac arrest due to Brugada syndrome: a case report and literature review. Journal of Shahid Sadoughi University of Medical Sciences 2013; 21(1): 113-7. [In Persian].

6. Eftekhari H. Case study of Brugada syndrome presenting initially as acute myocardial infarction. Int Emerg Nurs 2015; 23(4): 329-33. doi: 10.1016/j.ienj.2015.02.001.

7. Sieira J, Ciconte G, Conte G, Chierchia GB, de Asmundis C, Baltogiannis G, et al. Asymptomatic Brugada syndrome: clinical characterization and long-term prognosis. Circ Arrhythm Electrophysiol 2015; 8(5): 1144-50. doi: 10.1161/ circep.114.003044.

8. Ueoka A, Morita H, Watanabe A, Nakagawa K, Nishii $\mathrm{N}$, Nagase S, et al. Activation pattern of the polymorphic ventricular tachycardia and ventricular fibrillation on body surface mapping in patients with Brugada syndrome. Circ J 2016; 80(8): 1734-43. doi: 10.1253/circj.CJ-16-0124.

9. Morita H, Zipes DP, Wu J. Brugada syndrome: insights of ST elevation, arrhythmogenicity, and risk stratification from experimental observations. Heart Rhythm 2009; 6(11 Suppl): S34-43. doi: 10.1016/j.hrthm.2009.07.018.

10. Amin AS, Klemens CA, Verkerk AO, Meregalli PG, Asghari-Roodsari A, de Bakker JM, et al. Fever-triggered ventricular arrhythmias in Brugada syndrome and type 2 long-QT syndrome. Neth Heart J 2010; 18(3): 165-9. doi: 10.1007/bf03091755.

11. Matsuo K, Kurita T, Inagaki M, Kakishita M, Aihara N, Shimizu W, et al. The circadian pattern of the development of ventricular fibrillation in patients with Brugada syndrome. Eur Heart J 1999; 20(6): 465-70. doi: 10.1053/ euhj.1998.1332.

12. Mizumaki K, Fujiki A, Nishida K, Iwamoto J, Sakamoto T, Sakabe $\mathrm{M}$, et al. Postprandial augmentation of bradycardiadependent ST elevation in patients with Brugada syndrome. J Cardiovasc Electrophysiol 2007; 18(8): 839-44. doi: 10.1111/j.1540-8167.2007.00872.x.

13. Mizumaki K, Fujiki A, Tsuneda T, Sakabe M, Nishida K, Sugao M, et al. Vagal activity modulates spontaneous augmentation of ST elevation in the daily life of patients with Brugada syndrome. J Cardiovasc Electrophysiol 2004; 15(6): 667-73. doi: 10.1046/j.1540-8167.2004.03601.x.

14. Kasanuki H, Ohnishi S, Ohtuka M, Matsuda N, Nirei T, Isogai $\mathrm{R}$, et al. Idiopathic ventricular fibrillation induced with vagal activity in patients without obvious heart disease. Circulation 1997; 95(9): 2277-85. doi: 10.1161/01. cir.95.9.2277.

15. Noda T, Shimizu W, Taguchi A, Satomi K, Suyama K, Kurita $\mathrm{T}$, et al. ST-segment elevation and ventricular fibrillation without coronary spasm by intracoronary injection of acetylcholine and/or ergonovine maleate in patients with Brugada syndrome. J Am Coll Cardiol 2002; 40(10): 18417. doi: 10.1016/s0735-1097(02)02494-4.

16. Matsuo K, Shimizu W, Kurita $\mathrm{T}$, Inagaki M, Aihara N, Kamakura S. Dynamic changes of 12-lead electrocardiograms in a patient with Brugada syndrome. J Cardiovasc Electrophysiol 1998; 9(5): 508-12. doi: 10.1111/ j.1540-8167.1998.tb01843.x.

17. Miyazaki T, Mitamura H, Miyoshi S, Soejima K, Aizawa Y, Ogawa S. Autonomic and antiarrhythmic drug modulation of ST segment elevation in patients with Brugada syndrome. J Am Coll Cardiol 1996; 27(5): 1061-70. doi: 10.1016/07351097(95)00613-3. 